\title{
Contraceptive use as limiters and spacers among women of reproductive age in southwestern, Saudi Arabia
}

\author{
Mohammed A. Alsaleem, SBFM, ArBFM, Shamsun N. Khalil, PhD, Aesha F. Siddiqui, MD, DFM, \\ Maha M. Alzahrani, SBFM, Safar A. Alsaleem, SBFM, ArBFM.
}

\begin{abstract}

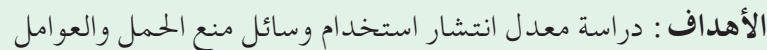

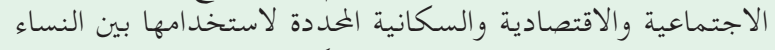

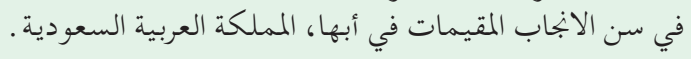

الطريقة: جمعت البيانات من خلال دراسة مقطعية تم إِجراؤه إِهاه

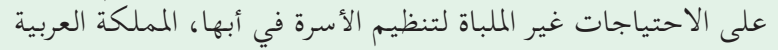

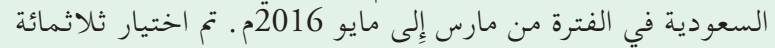

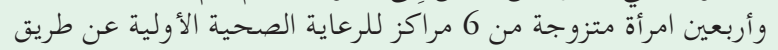

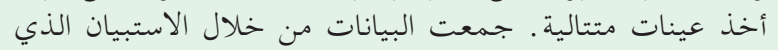

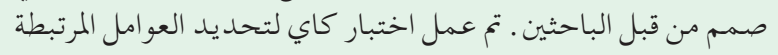

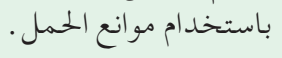

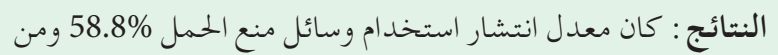

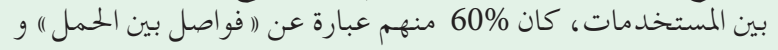

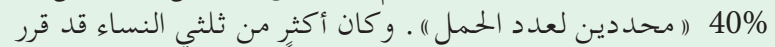

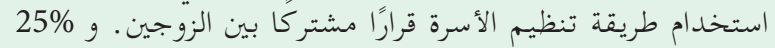

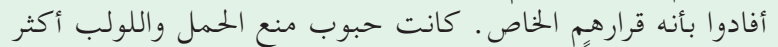

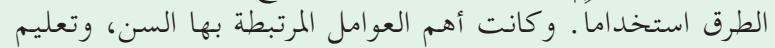

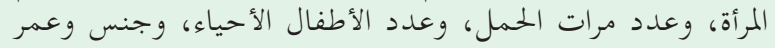

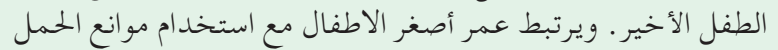

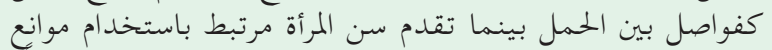

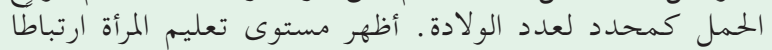

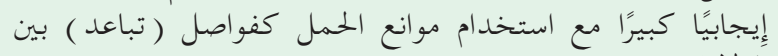

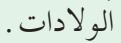

الحناتمة: أظهرت هذه الدراسة أن نسبة كبيرة من النساء في أبها

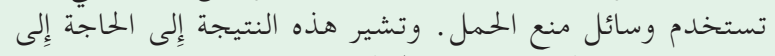

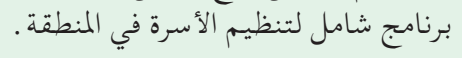

Objectives: To examine the prevalence, socioeconomic, and demographic determinants of contraceptive use among women of reproductive age residing in Abha, Kingdom of Saudi Arabia.

Methods: The data of this study was collected through a cross sectional survey conducted on unmet need for family planning in Abha, Kingdom of Saudi Arabia, between March and May 2016. Three hundred and seventy-four married women were recruited from 6 primary health care centers by a consecutive sampling technique. Data was collected via an intervieweradministered questionnaire. Chi-square test was carried out to identify the factors associated with contraceptive use.

Results: The prevalence of contraceptive use rate was $58.8 \%$. Among users, $60 \%$ were spacers and $40 \%$ were limiters. Among more than two-thirds of the women, the decision to use a family planning method was a joint decision of the couple; and 25\% reported it as their own decision. Oral pills and intrauterine contraceptive device (IUCD) were the most popular methods. The most significant associated factors were age, education of women, gravida, number of living children, gender, and age of the last child. Younger age was related with the spacers and older age with birth limiting. Woman's education level showed a significant positive association with birth spacing.

Conclusion: This study demonstrated that a sizable percentage of women in Abha, Kingdom of Saudi Arabia, are using contraceptions. This finding indicates the need of comprehensive family planning program in the region.

\section{Saudi Med J 2018; Vol. 39 (11): 1109-1115} doi: 10.15537/smj.2018.11.22817

From the Department of Family and Community Medicine (Alsaleem, Khalil, Siddiqui, Alsaleem), College of Medicine, King Khalid University, and from the Ministry of Health (Alzahrani), Abha, Kingdom of Saudi Arabia.

Received 24th August 2018. Accepted 22nd October 2018.

Address correspondence and reprint request to: Dr. Mohammed A. Alsaleem, Department of Family and Community Medicine, College of Medicine, King Khalid University, Abha, Kingdom of Saudi Arabia. E-mail:mabade@kku.edu.sa

ORCID ID: orcid.org/0000-0002-3205-1713 
T The Middle East has long been known for placing enormous importance on families. Over the past few decades, the region has witnessed rapid changes in the socio-demographic pattern of its population. Most of these changes have occured in the women, with many pursuing higher education and joining the workforce. These changes have revolutionized attitudes towards fertility beliefs and behaviors, with more couples opting the usage of contraceptive methods. ${ }^{1}$ The rates of contraceptive use have risen across the regions, reflecting a desire among most married couples for planned families. ${ }^{2,3}$ The Kingdom of Saudi Arabia has a high birth rate and a high total fertility rate. ${ }^{4}$ According to a report from the World Health Organization (WHO), the prevalence of contraceptive use rate in 2013 was $24 \% .^{5}$ Saudi studies from different regions have reported a variety of rates, ranging from $27-74.9 \% .6,7$ The pattern of contraceptive use in the country is also changing. Whereas previous studies reported contraceptive use was restricted to the urban and educated population. ${ }^{8,9}$ Recent studies have shown general increase in the adoption of contraceptive methods across all groups of the population with no significant differences based on socio-demographic factors. ${ }^{1}$ The national demographic survey in 2000 in Kingdom of Saudi Arabia concluded that there was no significant effect of women's participation in the labor force upon fertility. ${ }^{10}$ In Kingdom of Saudi Arabia several studies identified working status, maternal age, level of education, parity, family size, and breastfeeding as associated factors of family planning use. ${ }^{6,11,12}$

In a study from Qassim, Kingdom of Saudi Arabia, the majority of respondents indicated a desire to have at least 5 and as many as 10 children, while reporting a contraceptive prevalence of $40 \%$. These facts indicate the acceptance of the concept of birth spacing and the use of contraceptives in order to have the desired birth interval rather than to limit the number of births. Oral and intra-uterine contraceptives have been reported as the most preferred choices of contraceptives in the Kingdom of Saudi Arabia. ${ }^{6,12,13}$ With the current Saudi vision for development, the country needs to focus on its fertility indicators, as some studies have linked high fertility rate with underdevelopment. ${ }^{14}$ It is noteworthy that contraception is an essential tool for improvement in reproductive health and women's empowerment. ${ }^{15}$

Disclosure. Authors have no conflict of interests, and the work was not supported or funded by any drug company.
In the Kingdom of Saudi Arabia, a considerable number of fertile, married women do not use contraceptive methods. Moreover, many women who are using contraceptive methods do not have adequate knowledge of the proper use. ${ }^{12,16,17}$ Family planning is not extensively popular in Kingdom of Saudi Arabia, and the use of contraceptives are low compared to that in other developing countries. ${ }^{4,18}$ This study in Abha, Kingdom of Saudi Arabia, would help to provide a clearer portrait of the contraception use situation in southwestern Kingdom of Saudi Arabia, which could then be used to add depth to knowledge about the situation throughout Kingdom of Saudi Arabia.

The aim of the study is to identify the prevalence of contraceptive use in Kingdom of Saudi Arabia in terms of "spacer" and "limiters". It does so by examining the effect of different demographic, social, economic, and reproductive determinants on the fertility behavior of Saudi women. Such information would help health care managers to plan programs and promote the service of family planning in the country.

Methods. This is a cross sectional study conducted among 374 reproductive women in Abha city, Kingdom of Saudi Arabia between March-May 2016. Using simple random sampling, 6 out of 12 primary health care centers (PHCCs) were chosen. Assuming 50\% contraceptive user rate, the calculated sample size was 384. ${ }^{19}$ Then, following consecutive sampling technique 384 women were chosen, keeping equal number from each PHCC. Ten women refused to participate later, leading to final sample of 374 . In this study 'Limiters' are women who are using a method to avoid the birth of any more children while 'Spacers' are defined as women using a contraceptive method who want to wait 2 or more years before having their next child. ${ }^{20}$

An English questionnaire was developed after literature review, translated into Arabic, and retranslated to English to ensure its validity and consistency. The questionnaire included sociodemographic variables, reproductive history, and different aspects of contraceptive practice including types of contraceptive use, duration, and purpose of contraception. The purpose of using contraception is to either space the next pregnancy or limit the number of children.

Prior to conduct the final survey, a pilot study was conducted on 15 women to test the questionnaire's comprehensiveness and language as well as time required for the interview. According to the participants' feedback, the questionnaire was modified to fit the study objectives within the cultural ethos of Kingdom of Saudi Arabia. The results of the pilot study were 
excluded from the main study. Ethical permission was given from the research and ethical committee of King Khalid university in Abha, Kingdom of Saudi Arabia.

Data was collected by face-to-face interviews with the women by the researchers in the primary health care center during their waiting time for appointment. Confidentiality and anonymity were maintained through all research steps. Prior to the interview, respondents were informed about the aim and methodology of the study and verbal consent was taken.

Data analysis was performed using SPSS version 22.0 (IBM corp., Armonk, NY, USA). Descriptive statistics including frequency distribution and percentages, mean, range, and standard deviation were calculated. A Chi-square test was used to examine the relationship between variables. P-values $<0.05$ were considered significant.

Results. Table 1 represents the basic demographic and reproductive information of the respondents related to their contraceptive use. The mean age of the respondents who were using contraception was $32.7 \pm 6.8$ years, while for those who were not using contraception was $33.2 \pm 6.9$ years. Among women aged 30 years or less, $59.2 \%$ used contraception, as compared to $58.5 \%$ of those above 30 years. More than half of the women $(55 \%)$ with secondary school education reported using contraception as compared to $62 \%$ with a university degree. More working women (63.2\%) than housewives $(55.9 \%)$ were shown to use contraception. Regarding the husbands, no differences in the proportion of users were evident across different educational and occupational groups. Contraceptive use among different income groups showed no significant difference.

Regarding the reproductive characteristics of women, $63.3 \%$ multigravida women ( $>4$ times conception), $63 \%$ of women with more than 4 children, and $64.2 \%$ of women with their youngest child more than 2 years of age reported contraceptive use. None of the studied factors had a significant effect on the use of contraceptives except discussion of desired family size with the husband. Women who discussed desired family size with their husband had a significantly higher use rate of contraceptive method $(63.5 \%, p<0.001)$ than those who did not (36.9\%).

Table 2 illustrates the characteristics of family planning use among the study participants. From a total of 374 women, $220(58.8 \%)$ were found to be current contraceptive users, while $41.2 \%$ were not using contraception. The proportion of spacers among this group was $60 \%$, and limiters was $40.0 \%$. The ratio of spacers to limiters was approximately $3: 2$. A vast majority of women $(82.1 \%)$ reported that they discussed desired family size with their husband. More than two-thirds of the participants $(70.9 \%)$, reported that the decision to use a family planning method was a joint decision of the couple while around one fourth of the participants (25.5\%) reported it as their own decision. More than half of the women (55.5\%) who were using contraception reported having used it for less than a year. Regarding the type of contraceptive method, oral pill was the most popular choice $(48.6 \%)$ users, followed by intrauterine contraceptive device (IUCD) (33.2\%), natural methods (8.2\%), and condoms (5.5\%). Terminal method of ligation was used by only $4.5 \%$ women.

Table 3 represents factors associated with the use of family planning method among the study participants. All sociodemographic factors and obstetric characteristics were analyzed for their association with the purpose of family planning, namely, for spacing or limiting of births. The factors that were found to have a significant association with the purpose of family planning are age, women's education, gravid, number of living children, gender and age of the last child. Younger age was related with the birth spacing and older age with birth limiting. Women's educational level showed a significant association with birth spacing. Both women with a secondary education and women with a bachelor's-level education opted for birth spacing; however, the proportion is significantly higher among those women holding a bachelor's degree and above educated women (65.9\%, $p=0.028)$. Regarding the obstetric characteristics, almost threequarters of women $(73.4 \%)$ with lower gravidity chose birth spacing, which was significantly different than the proportion of multigravida women using birth spacing (25.8\%). A much larger proportion $(74.2 \%)$ of multigravida women had opted for birth limiting. The number of living children showed a significant relation with the purpose of family planning. Seventy-one percent of women with 4 children or less children used family method for spacing, while more than $82 \%$ of women with more than 4 children used family planning for limiting births. There was a significant difference in using the births spacing, if the gender of the last child was male $(p=0.019)$ as compared to female. A significantly higher proportion of women whose last child was 2 years of age or younger reported using family planning for birth spacing $(75.6 \%)$ as compared to women whose last child was more than 2 years of age (40.2\%). 
Table 1 - Basic sociodemographic and obstetric characteristics of the study population ( $N=374)$.

\begin{tabular}{|c|c|c|c|c|}
\hline Variable & $\begin{array}{c}\text { Contraceptive } \\
\text { (user) }\end{array}$ & $\begin{array}{c}\text { Contraceptive } \\
\text { (non-user) }\end{array}$ & Chi-square & $p$-value \\
\hline \multicolumn{5}{|l|}{ Age } \\
\hline$\leq 30$ & $93(59.2)$ & $64(40.8)$ & \multirow[t]{2}{*}{0.019} & \multirow[t]{2}{*}{0.89} \\
\hline$>30$ & $127(58.5)$ & $90(41.5)$ & & \\
\hline \multicolumn{5}{|l|}{ Education of woman } \\
\hline Up to secondary & $88(54.7)$ & $73(45.3)$ & \multirow[t]{2}{*}{2.05} & \multirow[t]{2}{*}{0.169} \\
\hline Graduate and above & $132(62.0)$ & $81(38.0)$ & & \\
\hline \multicolumn{5}{|l|}{ Education of husband } \\
\hline Up to secondary & $95(59.7)$ & $64(40.3)$ & \multirow{2}{*}{0.098} & \multirow[t]{2}{*}{0.832} \\
\hline Graduate and above & $125(58.1)$ & $90(41.9)$ & & \\
\hline \multicolumn{5}{|l|}{ Woman's occupation } \\
\hline Housewife & $124(55.9)$ & $98(44.1)$ & \multirow[t]{2}{*}{1.98} & \multirow[t]{2}{*}{0.15} \\
\hline Working & $96(63.2)$ & $56(36.8)$ & & \\
\hline \multicolumn{5}{|l|}{ Husband's occupation } \\
\hline Unemployed & $15(57.7)$ & $11(42.3)$ & \multirow[t]{2}{*}{0.015} & \multirow[t]{2}{*}{1.00} \\
\hline Working & $205(58.9)$ & $143(41.1)$ & & \\
\hline \multicolumn{5}{|l|}{ Monthly Family Income } \\
\hline$\leq 10000 \mathrm{SR}$ & $135(60.0)$ & $91(40.0)$ & \multirow[t]{2}{*}{0.323} & \multirow[t]{2}{*}{0.59} \\
\hline$>10000 \mathrm{SR}$ & $85(57.0)$ & $63(43.0)$ & & \\
\hline \multicolumn{5}{|l|}{ Gravida } \\
\hline$\leq 4$ & $158(57.2)$ & $118(42.8)$ & \multirow{2}{*}{1.08} & \multirow[t]{2}{*}{0.29} \\
\hline$>4$ & $62(63.3)$ & $36(36.7)$ & & \\
\hline \multicolumn{5}{|l|}{ Outcome of last pregnancy } \\
\hline Live birth & $202(58.9)$ & $141(41.1)$ & \multirow{2}{*}{0.008} & \multirow[t]{2}{*}{1.00} \\
\hline Other than live birth & $18(58.1)$ & $13(41.9)$ & & \\
\hline \multicolumn{5}{|l|}{ Any abnormal child } \\
\hline No & $212(59.1)$ & $147(40.9)$ & \multirow[t]{2}{*}{0.194} & \multirow[t]{2}{*}{0.79} \\
\hline Yes & $8(53.3)$ & $7(46.7)$ & & \\
\hline Age of the last child & & & & \\
\hline$\leq 2$ years & $123(55.2)$ & $100(44.8)$ & 3.06 & 0.08 \\
\hline$>2$ years & $97(64.2)$ & $54(35.8)$ & & \\
\hline Gender of the last child & & & & \\
\hline Boy & $110(57.3)$ & $82(42.7)$ & 0.382 & 0.59 \\
\hline Girl & $110(60.4)$ & $72(39.6)$ & & \\
\hline Number of living childre & & & & \\
\hline$\leq 4$ & $174(57.8)$ & $127(42.2)$ & 0.657 & 0.415 \\
\hline$>4$ & $46(63.0)$ & $27(37.0)$ & & \\
\hline Discussed the desired fam & & & & \\
\hline Yes & $196(63.6)$ & $112(36.5)$ & 16.69 & $<0.001$ \\
\hline No & $24(36.4)$ & $42(63.5)$ & & \\
\hline
\end{tabular}

Discussion. For the past several decades family planning programs and contraceptive prevalence rates have received increasing attention. Many countries in the Middle East, including Kingdom of Saudi Arabia, have witnessed increased contraceptive prevalence rates. The growing acceptance of contraception among Arab populations could be attributed to the increase in girls' education and participation in wider society, which is an adjunct to social changes such as delays in child bearing and the use of modern contraceptives. ${ }^{15}$

In the Middle Eastern context, most regional studies conducted outside Kingdom of Saudi Arabia have reported higher rates of contraceptive use than Kingdom of Saudi Arabia. Studies from Iran, Egypt, and Iraq also showed a high use of contraceptives. ${ }^{21-23}$ A study of
1130 Qatari women reported that $47.8 \%$ were using contraceptives. ${ }^{24}$ Moreover, previous studies conducted in Kingdom of Saudi Arabia showed that contraceptive use varies by region. A study in Al-Khobar, Kingdom of Saudi Arabia showed high use of contraceptives among Saudi women (74.8\%). ${ }^{7}$ In Taif, Kingdom of Saudi Arabia, the contraceptive prevalence rate among women of reproductive age was $67.7 \% .{ }^{25}$ In contrast, low levels of contraceptives use were reported from Qassim region (44.4\%) and Abha (27\%) in the Kingdom of Saudi Arabia. ${ }^{6,12}$ In the current study, from a total of 374 women, $220(58.8 \%)$ were found to be contraceptive users. This is in accordance with the prevalence found in other regions, except Abha, Kingdom of Saudi Arabia. The difference of prevalence in the same region 
may be explained by difference in methodology and participants.

Contraception is practiced by individuals for 2 reasons: to delay or space the next pregnancy or to limit the number of children. This idea has led to the development of 2 terms, "spacers" and "limiters" to identify, characterize, and distinguish the 2 primary types of contraceptive users. In surveys of contraceptive prevalence it is now a practice to break down the contraceptive prevalence rate into these 2 subcomponents. This information is important for family planning program managers and will be useful in selecting the appropriate methods for meeting the demand of contraceptive users. ${ }^{26}$ In the present study, $40 \%$ of the contraceptive users were limiters and $60 \%$ were spacers. Younger women opt for spacing while older women decide to limit the number of children. In the present study, this is clearly noticeable. As expected, the present study revealed that the number of spacers was greater among women of younger age, women with lower gravidity, lesser number of living children, and last child younger than 2 years of age. Women's educational level has also been demonstrated to be correlated with contraceptive use and our study findings are in concordance. Higher education has an indirect influence on contraceptive practices, as marriage is delayed and there are changes in reproductive behaviors. ${ }^{27,28}$ The

Table 2 - Characteristics of family planning use among respondents.

\begin{tabular}{lr}
\hline Variables & $\mathbf{n}(\%)$ \\
\hline Contraceptive use $(n=374)$ & $220(58.8)$ \\
$\quad$ Yes & $154(41.2)$ \\
No & \\
Purpose of contraceptive use $(n=220)$ & $132(60.0)$ \\
$\quad$ Spacing & $88(40.0)$ \\
Limiting & \\
Discussion of the desired family size $(n=374)$ & $307(82.1)$ \\
Yes & $67(17.9)$ \\
No & \\
Decision on family planning use $(n=220)$ & $156(70.9)$ \\
Both & $56(25.5)$ \\
Woman & $8(3.6)$ \\
Husband & \\
Duration of contraceptive use $(n=220)$ & $122(55.5)$ \\
$\leq 1$ year & $98(44.5)$ \\
$>1$ year & \\
Type of contraceptive method used $(n=220)$ & $107(48.6)$ \\
Oral pill & $73(33.2)$ \\
IUCD & $12(5.5)$ \\
Condom & $10(4.5)$ \\
Ligation & $18(8.2)$ \\
Natural methods & IUCD - intrauterine contraceptive device \\
\hline &
\end{tabular}

positive association found between female education and contraceptive uses has been consistently reported in several studies. ${ }^{29,30}$ Significantly higher use of spacing methods among women having sons indicates a desire for having more sons. Studies indicate that son's preference effects fertility, as couples continued to have children until they have had their desired number of boys. ${ }^{31-33}$ Al-Sheeha, ${ }^{12}$ stated that Saudi women accept the concept of birth spacing and use contraceptives in order to have the desired interval rather than to have fewer children. Contrary to this, our study found a positive association of birth limiting with higher gravida and higher number of living children. Total number of living children shows the same relation with contraception. A higher number of women with fewer children select methods for temporary contraception or spacing. By contrast, women with more children use or adopt permanent methods.

A noteworthy finding of this study is that a vast majority of women reported that they discussed desired family size with their husband; more than two-thirds of couples took this decision to use a family planning method jointly. This signifies that close communication between couples can influence contraceptive use. Our finding is in concordance with earlier studies that have established that couples who discuss family planning are more likely to use contraception and achieve their family planning goals than those who do not. ${ }^{33-35}$ In this study, one-fourth of the women confirmed that their contraceptive use was their own decision. This may be associated with the role of female education in empowering women and enhancing their autonomy and participation in decision-making. This is expected to be associated with increased use of modern contraceptives.

At the individual level, the factors reported to be associated with increased likelihood of using contraceptives are high parity, level of female education, level of husband's education, and the income level. ${ }^{36}$ A similar relationship has been reported by regional studies in Oman and Kingdom of Saudi Arabia. ${ }^{13,37}$ However, our study did not find such association. This may be due to differences in the population and data collection methods.

In this study, an oral pill was revealed as the most popular contraceptive choice, followed by IUCD and then natural methods. This reflects the pattern of contraceptive use in Kingdom of Saudi Arabia. ${ }^{6,12,13,25}$ oral contraceptive pills (OCP) and intrauterine device (IUD) are the most effective, easily available, and easy-to-use spacing methods, leading to their popularity among women. This study, like other studies in the Middle East, reported a low rate of condom use. The reason for low condom use could be that condoms 
Table 3 - Factors associated with purpose of family planning $(n=220)$.

\begin{tabular}{|c|c|c|c|c|}
\hline \multirow[t]{3}{*}{ Variables } & \multicolumn{2}{|c|}{ Purpose of family planning } & \multirow[t]{3}{*}{ Chi-square } & \multirow[t]{3}{*}{$P$-value } \\
\hline & Limiting births & Spacing births & & \\
\hline & \multicolumn{2}{|c|}{$\mathbf{n}(\%)$} & & \\
\hline \multicolumn{5}{|l|}{ Age } \\
\hline $\begin{array}{l}\leq 30 \text { years } \\
>30 \text { years }\end{array}$ & $\begin{array}{l}17(18.3) \\
71(55.9)\end{array}$ & $\begin{array}{l}76(81.7) \\
56(41.1)\end{array}$ & 31.67 & $<0.001$ \\
\hline \multicolumn{5}{|l|}{ Education of women } \\
\hline $\begin{array}{l}\text { Up to secondary level } \\
\text { Bachelor and above }\end{array}$ & $\begin{array}{l}43(48.9) \\
45(34.1)\end{array}$ & $\begin{array}{l}45(51.1) \\
87(65.9)\end{array}$ & 4.80 & 0.028 \\
\hline \multicolumn{5}{|l|}{ Gravida } \\
\hline $\begin{array}{l}\leq 4 \\
>4\end{array}$ & $\begin{array}{l}42(26.6) \\
46(74.2)\end{array}$ & $\begin{array}{l}116(73.4) \\
16(25.8)\end{array}$ & 42.06 & $<0.001$ \\
\hline \multicolumn{5}{|l|}{ Number of living children } \\
\hline $\begin{array}{l}\leq 4 \text { children } \\
>4 \text { children }\end{array}$ & $\begin{array}{l}50(28.7) \\
38(82.6)\end{array}$ & $\begin{array}{l}124(71.3) \\
8(17.4)\end{array}$ & 43.99 & $<0.001$ \\
\hline \multicolumn{5}{|l|}{ Gender of last child } \\
\hline $\begin{array}{l}\text { Boy } \\
\text { Girl }\end{array}$ & $\begin{array}{l}35(31.8) \\
53(48.2)\end{array}$ & $\begin{array}{l}75(68.2) \\
57(51.8)\end{array}$ & 6.14 & 0.019 \\
\hline \multicolumn{5}{|l|}{ Age of last child } \\
\hline $\begin{array}{l}\leq 2 \text { years } \\
>2 \text { years }\end{array}$ & $\begin{array}{l}30(24.4) \\
58(59.8)\end{array}$ & $\begin{array}{l}93(75.6) \\
39(40.2)\end{array}$ & 28.32 & $<0.001$ \\
\hline
\end{tabular}

are stigmatized in Middle Eastern culture due to their perceived connection with illicit sexual activities or the notion that they are incompatible with the teachings of Islam. In a Jordanian study, a majority of women reported that they were afraid to ask their partners to use a condom, and most of them reported that their partner refused to use condoms. ${ }^{38}$

The need for family planning services is increasing throughout the region because the number of women of reproductive age is growing and a large share of married women are using contraceptives.39 Several Middle Eastern countries have policies to improve rates of contraceptive use. Some countries have increased the availability of contraceptives, even subsidizing them, however not so in Kingdom of Saudi Arabia. Family planning should not be considered as a fertility control measure; it is critical for women 's health and their families and has an impact on a country's economic development. Currently, Saudi women in need of family planning methods obtain it from pharmacies or private clinics because of the absence of governmentsponsored services. Despite the absence of a national family planning program, there is ample evidence to support that there is a growing demand for family planning that indicates a need. ${ }^{40}$ The factors that act as a barrier to contraceptions can be eliminated by providing appropriate information, counseling, and contraceptive choices to married couples through a comprehensive national family planning program.
Study limitation. This study was limited to one city in the Kingdom of Saudi Arabia. Thus the findings of the study cannot be generalized to all Saudi women. Further research over a wider area is recommended.

In conclusion, despite the absence of an organized family planning services in Kingdom of Saudi Arabia, this study demonstrated that a sizable percentage of women are using contraceptions. This finding emphasizes that comprehensive family planning services is the need of the hour in Kingdom of Saudi Arabia.

Acknowledgment. The authors would like to thank the administrators in the 6 Primary Health Care Centers where the research has been conducted and to all participants for their cooperation.

\section{References}

1. al-Nahedh NN. The effect of sociodemographic variables on child-spacing in rural Saudi Arabia. East Mediterr Health J 1999; 5: 136-140.

2. Chichakli LO, Atrash HK, Musani AS, Johnson JT, Mahaini $\mathrm{R}$, Arnaoute S. Family planning services and programmes in countries of the Eastern Mediterranean Region. East Mediterr Health J 2000; 6: 614-624.

3. Roudi- Fahimi F. Women's reproductive health in the Middle East and North Africa. Population Reference Bureau MENA Policy Brief 2003.

4. DESA. World Urbanization Prospects: the 2007 Revision [Internet]. New York: United Nations; 2008 [Accessed December 10, 2007]. Available from: http://www.un.org/esa/ population/publications/wup2007/2007WUP_Highlights_ web.pdf 
5. World Health Organization. World Health Statistics 2011 [Internet]. Geneva: WHO; 2011 [Accessed December 10, 2017]. Available from: http://www.who.int/whosis/whostat/ EN_WHS2011_Full.pdf

6. Farheen A. Ever use of contraceptives among women attending primary health care centers at Abha, Saudi Arabia. International Journal of Current Research and Review 2013; 5: 26-32.

7. Al-Turki HA. Contraception: attitudes and experiences of Saudi Arabian women. Health Care Women Int 2011; 32: 134-139.

8. Fahimi R, Ashford LS. Men \& family planning in Africa. Washington (DC): Population Reference Bureau; 1996.

9. Omran AR, Roudi F. The Middle East population puzzle. Popul Bull 1993; 48: 1-40.

10. Kraif RM. Fertility in Saudi Arabia: levels and determinants. Proceedings of the XXIV General Population Conference; 2000 August 18-24; Salvador, Brazil.

11. al-Almaie SM. The pattern and factors associated with child spacing in eastern Saudi Arabia. J R Soc Promot Health 2003; 123: 217-221.

12. Al Sheeha M. Awareness and use of contraceptives among saudi women attending primary care centers in $\mathrm{Al}$-qassim, saudi arabia. Int J Health Sci (Qassim) 2010; 4: 11-21.

13. Abdel-Fattah M, Hifnawy T, El Said TI, Moharam MM, Mahmoud MA. Determinants of birth spacing among saudi women. J Family Community Med 2007; 14: 103-111.

14. Fujun J. Economic Growth. Birth policy and fertility: An Empirical Analysis Based on Cross-country Panel Data, Northwest Population. Northwest Population 2014; 5: 35-44.

15. Ndahindwa V, Kamanzi C, Semakula M, Abalikumwe F, HedtGauthier B, Thomson DR. Determinants of fertility in Rwanda in the context of a fertility transition: a secondary analysis of the 2010 Demographic and Health Survey. Reprod Health 2014; 11: 87.

16. Al-Mansour R, Sabra A, Hafez A. Contraception: Knowledge, attitude, and practice with special emphasis on contraceptive pills among Saudi Women at Al-Khobar city. Eastern Saudi Arabia. The Egyptian Journal of Community Medicine 2012; 30: 1-13.

17. Anjum S, Durgawale PM, Shinde M. Knowledge of contraceptives methods and appraisal of health education among married women. International Journal of Science and Research 2014; 3: 584-590.

18. Malalu K, Alfred K, Too R, Chirchir A. Determinants of use of modern family planning methods: A case of Baringo North District, Kenya. Science Journal of Public Health 2014; 2: 424-430.

19. Dahiru T, Aliyu A, Kene TS. Statistics in Medical Research: Misuse of Sampling and Sample Size Determination. Annals of African Medicine 2006; 5: 158-161.

20. WestoffCF, Koffman D. Birth spacing and limiting connections. DHS analytical studies No. 21. Maryland (USA): ICF Macro; 2010.

21. Asadi SK, Leng KS, Malina MN, Mat YS, Ahmadi A. Comparison of the determinant factors of using the contraceptive methods between rural and urban women in Shiraz County, Iran. Journal of Midwifery and Reproductive Health 2017; 5: 1041-1052.

22. Awadalla HI. Profile of contraception use among Egyptian women. Scholarly Journal of Scientific Research and Essay 2012; 1: 10-15.

23. Noaman AM. Descriptive study of family planning methods and factors influencing their usage among women attending Tikrit Teaching Hospital. Tikrit Medical Journal 2010; 16: 100-106.
24. Arbab AA, Bener A, Abdulmalik M. Prevalence, awareness and determinants of contraceptive use in Qatari women. East Mediterr Health J 2011; 17: 11-18.

25. Albezrah NA. Use of modern family planning methods among Saudi women in Taif, KSA. 2015; 4: 990-994.

26. Chowdhury RH. Unmet Need for Contraception in South Asia: Levels, Trends and Determinants. Asia-Pacific Population Journal 2001; 16: 3-22.

27. Bollen KA, Glnaville JL, Stecklov G. Socioeconomic status and class in studies of fertility and health in developing countries. An: Annual review of sociology. 2001; 27: 153-186.

28. Wong E. Women's Work, Fertility Level and Contraceptive Use: A Synthesis of Results from Bolivia, the Philippines and Zimbabwe [Internet]. Washington DC: The Policy Project; 2000 [Accessed]. Available from: http://www.policyproject. $\mathrm{com} / \mathrm{pubs} / \mathrm{commissionedresearch/fhi.pdf}$

29. Larsson C, Stanfors M. Women's education, empowerment, and contraceptive use in sub- Saharan Africa: findings from recent demographic and health surveys. African Popul Stud 2014; 28: 1022-1034.

30. Ahmed S, Creanga AA, Gillespie DG, Tsui AO. Economic status, education and empowerment: implications for maternal health service utilization in developing countries. PLoS One 2010; 5: e11190.

31. Shetty V, Upadhyay UD. Baltimore, Maryland, USA: Johns Hopkins Bloomberg School of Public Health; 2002. Birth spacing: three to five saves lives. Population reports, Series L, No. 13. Population Information Program.

32. Youssef RM. Duration and determinants of interbirth interval: community-based survey of women in southern Jordan. East Mediterr Health J 2005; 11: 559-572.

33. Tessema ZK. Husband-wife communication about family planning in Assosa town (Ethiopia) [dissertation]. Oslo (NO): University of Oslo; 2002.

34. Link CF. Spousal communication and contraceptive use in rural Nepal: an event history analysis. Stud Fam Plann 2011; 42: 83-92.

35. Kamal SM, Islam MA. Interspousal communication on family planning and its effect on contraceptive adoption in Bangladesh. Asia Pac J Public Health 2012; 24: 506-521.

36. Oginnila AB, Ahonsib BA, Adebajoa S. Trend and determinants of unmet need for family planning services among currently married women and sexually active unmarried women aged 15-49 in Nigeria (2003-2013). African Population Studies 2015; 29: 1483-1500.

37. Khraif R, Abdul Salam A, Al-Mutairi A, Elsegaey I, \& Ajumah, A. (2016). Dynamics of contraceptive use: A study of King Saud University women's staff, Riyadh. Middle East Fertility Society Journal, 1-9.

38. Alkhasawneh E, McFarland W, Mandel J, Seshan V. Insight into Jordanian thinking about HIV: knowledge of Jordanian men and women about HIV prevention. J Assoc Nurses AIDS Care 2014; 25: e1-e9.

39. Roudi-Fahimi F, Monem AA, Ashford L, El-Adawy M. Women's need for family planning in Arab countries. United Nations Population Fund. Population Reference Bureau 2012; July: 8.

40. Khalil SN, Al-Zahrani MM, Siddiqui AF. Unmet need and demand for family planning among married women of Abha, Aseer Region in Saudi Arabia. Middle East Fertility Society Journal 2017; 23: 31-36. 